\title{
Relationship between somatization and psychiatric symptoms, especially anxiety, depression, alexithymia, and severity of addiction in male patients with alcohol and heroin addiction
}

\author{
Muhammed Hakan Aksu' ${ }^{\oplus}$, Safak Yalcin Sahiner ${ }^{2 \oplus}$, Ismail Volkan Sahiner ${ }^{2 \oplus}$, Buket Koparal ${ }^{3 \oplus}$, Cisem Utku $^{4 \oplus}$, \\ Behcet $\operatorname{Cosar}^{4 \oplus}$, Zehra Arikan ${ }^{4}$
}

${ }^{1}$ Yildirim Beyazit University, Yenimahalle Teaching and Research Hospital, Department of Psychiatry, Ankara - Turkey

${ }^{2}$ Dr. Abdurrahman Yurtaslan Oncology Hospital, Department of Psychiatry, Ankara - Turkey

${ }^{3}$ Recep Tayyip Erdogan University, Training and Research Hospital, Department of Psychiatry, Rize - Turkey

${ }^{4}$ Gazi University, Department of Psychiatry, Ankara - Turkey

\begin{abstract}
Objective: There are differences among studies examining comorbid somatization in alcohol and heroin addicts. The literature is unclear whether substance use disorders are related with somatization symptoms or with a high rate of alexithymia, depression, and anxiety associated with somatization. Therefore, the primary aim of this study was to compare heroin and alcohol addicts with regard to comorbidity of somatization and other psychiatric symptoms. In addition, we aimed to evaluate the relationship between somatization, addiction severity, depression, anxiety and alexithymia levels.

Method: A total of 170 male outpatients, of whom 79 had been diagnosed as alcohol dependent and 91 as opiate dependent, were included in the study. A Sociodemographic Data Form, Addiction Profile Index, Symptom Checklist 90, and Toronto Alexithymia Scale-20 were administered to the patients.

Results: Somatization, depression, anger and hostility, interpersonal sensitivity, and psychoticism were significantly higher in heroin addicts than in alcohol addicts. In a stepwise linear regression model with somatization symptoms as the dependent variable and addiction severity, anxiety, depression, obsessive compulsive, anger and hostility, phobic anxiety, interpersonal sensitivity, psychoticism, paranoia, and alexithymia symptoms as independent variables, anxiety symptoms and alexithymia were found to be positive predictors of somatization symptoms.

Conclusion: It needs to be considered that in addictions to different substances, different psychiatric comorbid symptoms may occur. In addition, it is recommended that heroin- or alcohol-addicted patients with high somatic symptoms should be screened for anxiety disorders and alexithymic personality traits.
\end{abstract}

Keywords: Alexithymia, anxiety, depression, somatization, substance dependence

How to cite this article: Aksu MH, Yalcin Sahiner S, Sahiner IV, Koparal B, Utku C, Cosar B, Arikan Z. Relationship between somatization and psychiatric symptoms, especially anxiety, depression, alexithymia, and severity of addiction in male patients with alcohol and heroin addiction. Dusunen Adam The Journal of Psychiatry and Neurological Sciences 2020;33:120-129.

Correspondence: Muhammed Hakan Aksu, Yenimahalle Egitim ve Arastirma Hastanesi, Psikiyatri Klinigi, Yildirim Beyazit Universitesi, Yeni Bati Mah. 2026. Cd. 2367. Sokak No: 4, 06370 Batıkent/Yenimahalle, Ankara - Turkey

E-mail: mhknks@gmail.com

Received: November 13, 2019; Revised: January 24, 2020; Accepted: March 27, 2020 


\section{INTRODUCTION}

Epidemiological studies have established a high incidence of mental disorders and alcohol and substance use disorders in adults with a great degree of comorbidity (1-3). Psychiatric comorbidities reduce treatment compliance in patients with alcohol and substance use disorders and increase relapse and severity of both conditions (4). Therefore, identifying and treating comorbidities is of particular importance.

Somatization has been defined as a set of physical symptoms that cannot be explained medically even after adequate physical examination and tests (5). At the same time, the experience of bodily complaints in response to psychosocial stress is reflected in a propensity to establish contact and therefore seek medical help (6). Duration and intensity of somatization, degree and severity of comorbid mood disorder, and the individual's capacity to identify and describe feelings vary widely between cases (7). It has been suggested that symptoms of somatization are highly related with alcohol use, and somatic symptoms have been found to be predictors for future alcohol use (8). Ross et al. (9), using Symptom Checklist-90 (SCL90) to study the correlation between severity of psychiatric symptoms and retention in treatment in 414 patients with substance use disorder, found somatization to be the only set of symptoms correlated with dropout from treatment. A field study by Tien et al. (10) to establish the relation between somatization symptoms and alcohol use determined that an increase in the number of somatization symptoms amplified the risk of excessive alcohol consumption. Studies in the literature comparing patients with cocaine, heroin, hallucinogen, and alcohol use disorder found somatization symptoms at various levels $(10,11)$.

Alexithymia is a multifaceted personality trait characterized by difficulties identifying subjective emotional states and a limited capability to explain these emotions to other persons (12). Accordingly, they manifestly struggle with limited success to manage their emotions effectively (13). Previous studies demonstrated a correlation between alexithymia and the development of addiction behaviors (14). In addition, depending on the type of substance used, this trait may lead not only to a negative prognosis but also to a tendency towards relapse (15). Studies examining alexithymia and comorbid somatization in alcohol and heroin addiction have come to different conclusions (16-19). Furthermore, high-level correlations between basic addiction symptoms and other psychiatric disease symptoms have been shown in the research (11). There are also indications suggesting that depression and anxiety are correlated or associated with somatization and alexithymia (20-23). Data in the literature are not unambiguous regarding the question if substance use disorders are correlated with individuals' somatization or rather with depression and anxiety that often accompany somatization (24).

From this starting point, we wish to propose 2 hypotheses. Our first hypothesis assumes that the psychiatric symptoms accompanying alcohol and heroin addiction differ from one another. According to our second hypothesis, symptoms of anxiety, depression, alexithymia, and severity of addiction unlike other psychiatric symptoms - affect symptoms of somatization in alcohol and heroin addictions.

\section{METHOD}

\section{Study Sample}

Included in the study were a total of 170 consecutive male outpatients followed at the AMATEM Policlinic of the Psychiatry Department of Gazi University's Medical Faculty Hospital after completing detoxification. Of these patients, 79 had been diagnosed with alcohol addiction according to the criteria of ICD10 and 91 with heroin addiction.

\section{Inclusion Criteria}

1. Age between 18 and 65 years and male sex,

2. Giving informed consent,

3. Fulfilling the ICD-10 criteria for alcohol/heroin addiction, respectively,

4. At least 2 weeks' abstinence from alcohol or substance use.

\section{Exclusion Criteria}

1. Any kind of physical impairment,

2. Being in a state of alcohol/substance withdrawal, intoxication, or delirium tremens,

3. Illiteracy,

4. Mental retardation,

5. Dementia or any other organic mental disorder.

\section{Ethics Committee Approval}

The study was approved by the ethics committee of Gazi University, date February 2, 2017, research code number 2017-85.

\section{Measures}

Sociodemographic Data Form: A demographic data form prepared by the researcher was used to record 
personal information of the study participants (age, sex, educational status, etc.).

Addiction Profile Index (API) Interview Form: API is an instrument developed to measure various dimensions of addiction and its severity. It is a selfreport form consisting of 37 items and 5 subscales. The subscales measure characteristics of substance use, dependency diagnosis, effects of substance use on the user, craving, and the motivation to quit using substances. In the reliability analysis, Cronbach's alpha coefficient was 0.89 for the entire scale and ranged from 0.63 to 0.86 for the subscales. Item-total score correlation coefficients were between 0.42 and 0.89 . In the split-half test correlations for the entire instrument, the Spearman-Brown coefficient was 0.83 . Exploratory factor analysis found 4 factors explaining $52.39 \%$ of the total variance $(25,26)$.

Symptom Checklist-90-Revised (SCL 90-R): SCL$90-\mathrm{R}$ is a symptom screening tool developed by Derogatis et al. consisting of 90 items assessed on a 5-point Likert-type self-rating scale measuring the distress level manifesting itself with psychiatric symptoms. Each item is scored between 0 and 4 points (27). The scale is structured to assess 10 different symptom dimensions: somatization, obsessivecompulsive traits, interpersonal sensitivity, depression, anxiety, anger and hostility, phobic anxiety, paranoid ideation, psychoticism, and an additional scale. The General Symptom Index demonstrates the general level of wellbeing and functionality. It is calculated by dividing the total score of all subscales by 90 . The instrument has been adapted to Turkish by Dag (28).

Toronto Alexithymia Scale-20 (TAS-20): The short form of the TAS-20 was developed by Bagby et al. (29); validity and reliability of the Turkish version was studied in 2009 by Gulec et al. (30). TAS-20 is a selfreport instrument consisting of 20 items scored between 1 and 5 on a Likert-type scale, including three subscales: difficulties identifying feelings, difficulties describing feelings, and externally oriented thinking. A higher score indicates a greater alexithymic tendency. Cronbach's alpha for the total instrument was 0.78 , with values for the subscales between 0.57 and 0.80 . Confirmatory factor analysis found a 3-factor structure of the alexithymia construct (30).

\section{Statistical Analyses}

Statistical evaluation was carried out using SPSS version 15.0 (IBM). For all assessments, parametric tests were used. Sociodemographic data were evaluated using descriptive analyses, comparison between groups was performed with t-test and chi-square test, and correlations between dependent variables were established with Pearson correlation analysis methods. To compare parametric assumptions for the correlation between numerical variables, Pearson correlation was used. Using a multivariate linear regression model, the independent effects of different predictors on the somatization symptoms were investigated in the model. A value of $\mathrm{p}<0.05$ was considered statistically significant.

\section{RESULTS}

Disease characteristics and sociodemographic data for 170 male patients with alcohol $(n=79)$ and heroin addiction $(n=91)$, respectively, are presented in Table 1 . Participants in the heroin addiction group (mean age: $25.09 \pm 5.95$ years) were significantly younger than alcohol addicts (mean age: $44.75 \pm 11.66$ years) $(\mathrm{t}=$ -13.532, $\mathrm{p}<0.001$ ). Comparing educational status, $4.4 \%$ of the heroin addicts had only completed primary school, $36.3 \%$ middle school, $47.3 \%$ high school, and $12.1 \%$ university, while $12.7 \%$ of the alcohol addicts had finished after primary school, $10.1 \%$ after middle school, $39.2 \%$ had graduated from high school, and $38 \%$ had a university degree. A significantly higher proportion of alcohol addicts were married $\left(\chi^{2}=25.50\right.$, $\mathrm{df}=2, \mathrm{p}<0.001)$. The mean monthly income of alcohol addicts was significantly higher $(\mathrm{t}=-4.85, \mathrm{p}<0.001)$.

Scores reached on the instruments administered have been compared between patients addicted to heroin and those addicted with alcohol; results are presented in Table 2.

Heroin addicts scored significantly higher than alcohol addicts on the SCL-90 subscales somatization $(\mathrm{t}=2.544, \mathrm{p}<0.05)$, interpersonal sensitivity $(\mathrm{t}=2.187$, $\mathrm{p}<0.05)$, depression $(\mathrm{t}=2.202, \mathrm{p}<0.05)$, anger and hostility $(\mathrm{t}=2.768, \mathrm{p}<0.05)$, psychoticism $(\mathrm{t}=2.687$, $\mathrm{p}<0.01)$, and SCL-90 total score $(\mathrm{t}=2.396, \mathrm{p}<0.05)$ while reaching a significantly lower API total score $(t=-2.310$, $\mathrm{p}<0.05)$.

No significant difference was found for TAS and subscales and the SCL-90 subdimensions anxiety, obsessive-compulsive, phobic anxiety, and paranoia.

Table 3 shows the mean scores and standard deviation for SCL-90 somatization, depression, and anxiety subscales and TAS and API scores for all of the 170 participants. Table 4 shows the results of stepwise linear regression analysis, using the SCL-90 subtest somatization as the dependent variable. Independent variables are all SCL-90 subtests other than 
Table 1: Sociodemographic and clinical characteristics of alcohol- and heroin-addicted participants

\begin{tabular}{|c|c|c|c|c|c|c|c|}
\hline & \multicolumn{2}{|c|}{$\begin{array}{l}\text { Heroin addiction } \\
\qquad(n=91)\end{array}$} & \multicolumn{2}{|c|}{$\begin{array}{l}\text { Alcohol addiction } \\
(n=79)\end{array}$} & \multirow[b]{2}{*}{$\chi^{2}$} & \multirow[b]{2}{*}{ Degrees of freedom } & \multirow[b]{2}{*}{$\mathbf{p}$} \\
\hline & $\mathbf{n}$ & $\%$ & $\mathbf{n}$ & $\%$ & & & \\
\hline Marital status & & & & & 26.50 & 2 & $<0.001$ \\
\hline Married & 20 & 22 & 48 & 60.8 & & & \\
\hline Single & 71 & 78 & 31 & 39.2 & & & \\
\hline Employment status & & & & & 0.21 & 1 & 0.755 \\
\hline Unemployed & 55 & 60.4 & 45 & 56.9 & & & \\
\hline Working & 36 & 39.6 & 34 & 43.1 & & & \\
\hline Educational status & & & & & 27.85 & & $<0.001$ \\
\hline Primary school & 4 & 4.4 & 10 & 12.7 & & & \\
\hline Middle school & 33 & 36.3 & 8 & 10.1 & & & \\
\hline High school & 43 & 47.3 & 31 & 39.2 & & & \\
\hline University & 11 & 12.1 & 30 & 38 & & & \\
\hline \multicolumn{8}{|l|}{ Drug use } \\
\hline Buprenorphine+naloxone & 70 & 76.9 & 0 & 0 & & & \\
\hline Naltrexone & 19 & 20.9 & 0 & 0 & & & \\
\hline Antidepressant & 1 & 1.1 & 53 & 67.1 & & & \\
\hline No drug use & 1 & 1.1 & 26 & 32.9 & & & \\
\hline \multicolumn{8}{|l|}{ Substance used first } \\
\hline Marijuana & 76 & 83.5 & 0 & 0 & & & \\
\hline Other substances & 15 & 16.5 & 0 & 0 & & & \\
\hline \multirow[t]{2}{*}{ Alcohol } & 0 & 0 & 79 & 100 & & & \\
\hline & Mean & $\begin{array}{l}\text { Standard } \\
\text { deviation }\end{array}$ & Mean & $\begin{array}{l}\text { Standard } \\
\text { deviation }\end{array}$ & $\mathbf{t}$ & $\begin{array}{l}\text { Degrees of } \\
\text { freedom }\end{array}$ & $\mathbf{p}$ \\
\hline Age & 25.09 & 5.95 & 44.75 & 11.66 & 13.53 & 168 & $<0.001$ \\
\hline Monthly income & 1006.04 & 1076.05 & 3429.11 & 4321 & -4.85 & 168 & $<0.001$ \\
\hline
\end{tabular}

somatization, TAS, and API. Stepwise linear regression analysis found anxiety and alexithymia to have a predictive effect on symptoms of somatization.

\section{DISCUSSION}

This study found a higher mean age for alcohol addicts than for heroin addicts. A number of studies show the mean age of patients presenting to a hospital for alcohol addiction to be higher than for other groups of substances. As a possible explanation, it has been emphasize that alcohol use is more accepted in society and detrimental effects emerge at a later age $(31,32)$. In addition, patients with substance use disorder are exposed to a higher risk of early mortality compared to control groups from the population with similar demographic characteristics (33); reduced life expectancy in opiate addiction may thus also have affected the study sample.
Similar to other studies, alcohol addicts in our sample were more likely to be married than heroin addicts $(31,34)$. This might be explained with the higher age of alcohol addicts and greater social acceptance as well as later occurrence of detrimental effects.

Most participants of our study were high school graduates. However, there are studies finding no significant difference in the level of education between the two groups. On the other hand, there are studies emphasizing the low education levels of alcohol and substance addicts (35). The contrasting findings in our study might be explained with the 12-year compulsory education introduced prior to our research and the setting of our study in a university hospital where the probability for patients to be from a higher socioeconomic class is greater.

The monthly income of alcohol addicts in our study was greater than that of heroin addicts. This result shows that the characteristics of addiction change at 
Table 2: Comparison of data from groups using independent t-test

\begin{tabular}{|c|c|c|c|c|c|c|c|c|}
\hline Instruments & Group & $\mathbf{n}$ & Mean & SD & df & $\mathbf{t}$ & $\mathbf{p}$ & Cohen's d \\
\hline \multirow[t]{2}{*}{ Addiction Profile Index } & Heroin addiction & 91 & 6.71 & 0.8 & 168 & $-2.310^{*}$ & 0.022 & 0.36 \\
\hline & Alcohol addiction & 79 & 7.06 & 1.1 & & & & \\
\hline \multicolumn{9}{|l|}{ Toronto Alexithymia Scale } \\
\hline \multirow[t]{2}{*}{ Difficulties identifying feelings } & Heroin addiction & 91 & 16.36 & 6.86 & 168 & 0.962 & 0.338 & 0.14 \\
\hline & Alcohol addiction & 79 & 15.32 & 7.26 & & & & \\
\hline \multirow[t]{2}{*}{ Difficulties describing feelings } & Heroin addiction & 91 & 12.79 & 4.65 & 168 & 0.099 & 0.921 & 0.001 \\
\hline & Alcohol addiction & 79 & 12.72 & 4.53 & & & & \\
\hline \multirow[t]{2}{*}{ Externally oriented thinking } & Heroin addiction & 91 & 22.9 & 3.44 & 168 & 0.885 & 0.377 & 0.13 \\
\hline & Alcohol addiction & 79 & 22.38 & 4.14 & & & & \\
\hline \multirow[t]{2}{*}{ Total } & Heroin addiction & 91 & 52.06 & 10.8 & 168 & 0.873 & 0.384 & 0.13 \\
\hline & Alcohol addiction & 79 & 50.42 & 13.28 & & & & \\
\hline \multicolumn{9}{|l|}{ Symptom Checklist-90 } \\
\hline \multirow[t]{2}{*}{ Somatization } & Heroin addiction & 91 & 16.13 & 10.06 & 168 & $2.544^{*}$ & 0.012 & 0.38 \\
\hline & Alcohol addiction & 79 & 12.47 & 8.66 & & & & \\
\hline \multirow[t]{2}{*}{ Obsessive-compulsive } & Heroin addiction & 91 & 14.77 & 8.43 & 168 & 1.495 & 0.137 & 0.22 \\
\hline & Alcohol addiction & 79 & 12.9 & 7.87 & & & & \\
\hline \multirow[t]{2}{*}{ Interpersonal sensitivity } & Heroin addiction & 91 & 12.99 & 8.74 & 168 & $2.187^{*}$ & 0.030 & 0.33 \\
\hline & Alcohol addiction & 79 & 10.22 & 7.8 & & & & \\
\hline \multirow[t]{2}{*}{ Depression } & Heroin addiction & 91 & 19.92 & 13.27 & 168 & $2.202^{*}$ & 0.029 & 0.33 \\
\hline & Alcohol addiction & 79 & 15.73 & 11.53 & & & & \\
\hline \multirow[t]{2}{*}{ Anxiety } & Heroin addiction & 91 & 11.89 & 9.4 & 168 & 1.673 & 0.096 & 0.25 \\
\hline & Alcohol addiction & 79 & 9.61 & 8.39 & & & & \\
\hline \multirow[t]{2}{*}{ Anger and hostility } & Heroin addiction & 91 & 8.33 & 6.64 & 168 & $2.768^{* *}$ & 0.006 & 0.42 \\
\hline & Alcohol addiction & 79 & 5.86 & 4.96 & & & & \\
\hline \multirow[t]{2}{*}{ Phobic anxiety } & Heroin addiction & 91 & 4.54 & 4.62 & 168 & 1.311 & 0.192 & 0.2 \\
\hline & Alcohol addiction & 79 & 3.57 & 4.96 & & & & \\
\hline \multirow[t]{2}{*}{ Paranoia } & Heroin addiction & 91 & 7.94 & 5.36 & 168 & 1.238 & 0.218 & 0.18 \\
\hline & Alcohol addiction & 79 & 6.97 & 4.86 & & & & \\
\hline \multirow[t]{2}{*}{ Psychoticism } & Heroin addiction & 91 & 8.9 & 8.29 & 168 & $2.687^{* *}$ & 0.008 & 0.41 \\
\hline & Alcohol addiction & 79 & 5.82 & 6.64 & & & & \\
\hline \multirow[t]{2}{*}{ Total } & Heroin addiction & 91 & 116.18 & 71.76 & 168 & $2.396^{*}$ & 0.018 & 0.36 \\
\hline & Alcohol addiction & 79 & 91.62 & 61.84 & & & & \\
\hline
\end{tabular}

${ }^{*} \mathrm{p}<0.05,{ }^{* *} \mathrm{p}<0.01, \mathrm{SD}$ : Standard deviation, df: Degrees of freedom

different economic income levels. Several studies reported unemployment levels among addicts of $12-38 \%$, higher among substance addicts than among alcohol addicts $(31,36)$. As we did not find a significant difference in unemployment, the addiction may be thought to have caused a loss of functionality irrespective of the substance used.

In the results of this study, symptoms of somatization, depression, anger and hostility, interpersonal sensitivity, and psychoticism have been significantly more prevalent in heroin addicts than in alcohol addicts, thus supporting our first hypothesis: Psychiatric symptoms accompanying heroin and alcohol addictions show differences in these areas.

Subtest scores measuring somatization have been found significantly higher in heroin addicts than in alcohol addicts. A study comparing 2314 alcohol, heroin, and cocaine addicts on the basis of SCL-90 found no significant difference in somatization between alcohol addicts $(22.7 \%)$ and heroin addicts $(24.4 \%)$ (11). The difference found in the current study might be explained with the great intensity of withdrawal 


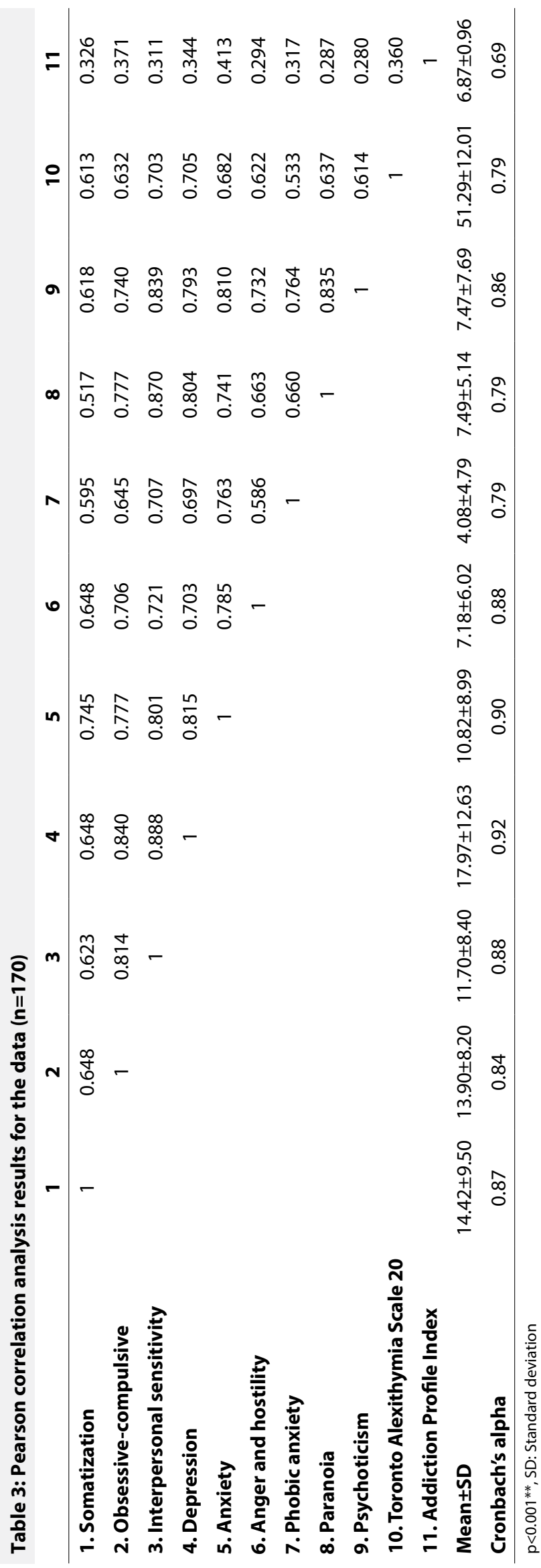

symptoms impacting the daily lives of heroin-addicted patients (1). One study showed a correlation between an increase in the substance addicts' remission periods and an improvement of their physical health state (37). A study using SCL-90 to compare heroin, alcohol, and cocaine addicts documented that the strongest factor to single out heroin addicts was somatic symptoms (11). In this study, $76.9 \%$ of heroin addicts in the sample were still in buprenorphine-naloxone treatment, and withdrawal symptoms due to partial agonist related to dose reductions during treatment may manifest as somatic symptoms, which, together with heroin addicts' excessive withdrawal symptoms in their daily lives, might account for this observation (1).

Subtest scores for interpersonal sensitivity were significantly higher in heroin addicts than in alcohol addicts. The younger age of heroin addicts in our study and their lower socioeconomic level may have increased their interpersonal sensitivity, which might be interpreted to mean that heroin addicts are less protected from interpersonal stress, an important predictor for the risk of substance abuse and relapse (38).

Depression subtest scores were significantly higher in heroin addicts compared to alcohol addicts. Some studies did not find a significant difference between depression levels in heroin and alcohol addicts $(11,39)$. Our study may have been affected by the exclusive enrolment of outpatients and the lower income level of heroin addicts. Contradictory results suggest the existence of more than one mechanism affecting addiction and depression jointly (40).

Anger and hostility subtest scores were also significantly higher in heroin addicts than in alcohol addicts. One study comparing substance and alcohol addiction in young adults using the Buss-Perry Aggression Questionnaire detected a significantly higher total aggression score in heroin addicts (41). It appears that the younger age and greater levels of depression and interpersonal sensitivity in heroin addicts may result in a lower inhibition threshold and an increase in anger levels.

The more frequent observation of psychotic symptoms in heroin addicts in our study could be related with the first substance used, which in the great majority of heroin addicts is marijuana. Studies report an increased prevalence of schizophrenia and other psychotic disorders among users of illegal substances like marijuana (42).

As we did not find studies in the literature comparing alexithymia between heroin and alcohol addicts directly, this aspect is harder to discuss. While 
Table 4: Stepwise linear regression model with somatization symptoms as dependent variable in alcohol and heroin addiction $(\mathbf{n}=170)$

\begin{tabular}{|c|c|c|c|c|c|c|c|c|c|}
\hline \multirow[t]{2}{*}{ Model } & \multicolumn{2}{|c|}{$\begin{array}{l}\text { Unstandardized } \\
\text { coefficients }\end{array}$} & \multirow{2}{*}{$\begin{array}{c}\begin{array}{c}\text { Standardized } \\
\text { coefficients }\end{array} \\
\text { Beta }\end{array}$} & \multirow[t]{2}{*}{$\mathbf{t}$} & \multirow[t]{2}{*}{$\mathbf{p}$} & \multirow[t]{2}{*}{$\mathbf{R}$} & \multirow[t]{2}{*}{$\mathbf{R 2}$} & \multirow[t]{2}{*}{ Ajdusted R2 } & \multirow[t]{2}{*}{ R2 change } \\
\hline & B & $\begin{array}{l}\text { Standard } \\
\text { error }\end{array}$ & & & & & & & \\
\hline \multicolumn{10}{|l|}{ Step 1} \\
\hline Anxiety & 0.793 & 0.055 & 0.745 & 14.462 & 0.000 & 0.745 & 0.555 & 0.552 & 0.555 \\
\hline \multicolumn{10}{|l|}{ Step 2} \\
\hline Anxiety & 0.651 & 0.073 & 0.611 & 8.865 & 0.000 & 0.758 & 0.575 & 0.570 & 0.021 \\
\hline Alexithymia & 0.156 & 0.055 & 0.196 & 2.841 & 0.005 & & & & \\
\hline
\end{tabular}

Dependent variable: SCL-90 Somatization subtest, $\mathrm{p}<0.05^{*}, \mathrm{p}<0.001^{* *}$

alexithymia is known to play an important role in addiction, findings of our study suggests that this role might be more related with addiction as such rather than with the addictive substance.

In the comparison of effect size between the 2 groups, even in results with a p value $<0.05$ Cohen's $\mathrm{d}$ ranged from 0.33 to 0.42 , indicating a low-to-moderate significance level for the differences between the groups.

To test the second hypothesis, a stepwise linear regression model was used to assess the factors predicting somatization in alcohol and heroin addicts: all SCL-90 subscales other than somatization, TAS, and API. The model found that anxiety and alexithymia symptoms predicted somatization at a significant level. Based on this result, we can consider the second hypothesis partly confirmed. This hypothesis had assumed that symptoms of depression and severity of addiction would affect somatization, which was not observed, while anxiety and alexithymia symptoms were found to be predictors. Other psychiatric symptoms included in the regression were not found to have a predictive effect. Assessing factors affecting somatization in alcohol and heroin addicts is important, given that its presence is evaluated as a factor related to retention in treatment, dropout, or relapse. Furthermore, it is important to note that the presence of somatization symptoms is to a high degree related with psychiatric and social morbidity (43). In addition, known somatization symptoms are considered to be helpful in determining excessive alcohol consumption and potential indicators for concurrent and future risk of excessive alcohol use (10). The alcohol and substance addicts making up the sample of this study are a population where emotional issues are less observed than behavioral problems. Somatic symptoms as distress markers and precursors of noncompliance can be more pronounced (43).
Some studies in the general population have demonstrated correlations between anxiety, depression, and somatic symptoms generally. In ca. $30 \%$ of patients presenting with somatization symptoms, depression or anxiety disorder have been identified (44). The correlation between somatization, anxiety, and depression is conspicuous in non-addicted individuals. A similar correlation is observed to be present in alcohol and substance addicts. One study dedicated to this relation assessed the nature and prevalence of somatization and related psychiatric symptoms in a sample of patients who had quit substance use. In the addicts, somatization, depression, and anxiety symptoms were observed at a high level. In addition, significant interscale correlations between depression, anxiety, and somatization were obtained: between depression and anxiety $(\mathrm{r}=0.63, \mathrm{p}<0.001)$, depression and somatization $(\mathrm{r}=0.46, \mathrm{p}<0.001)$, and anxiety and somatization $(r=0.60, p<0.001)(43)$. These results support the data from our study. These findings can be interpreted to mean that somatization, depression, and anxiety are present in addicted individuals.

A study examining the relation between addiction and somatic symptoms found substance addiction to be related with a sub-threshold somatic symptom state known as SSI4,6 (Somatic Symptom Index at least category 4 in males and at least 6 in females) (45). For the relation between substance addiction and SSI4,6, an odds ratio of 3.53 has been reported (46). However, different data are found in the literature. Analyzing the data from the Epidemiologic Catchment Area (ECA) study in the USA, somatization symptoms were found to have a very weak correlation with substance addiction and the highest correlation with major depression and anxiety disorder $(18,47)$. A more recent study based on data from 4 ECA sites found an increase in alcohol consumption in relation with a rise in the number of somatization symptoms (10). In our study, we examined 
somatization symptoms in alcohol and heroin addicts in a multiple linear regression model and found them to be related with alexithymia and anxiety. On the basis of this result, it can be assumed that the data from this sample are similar to the ECA data (18). However, other studies observed differences in somatization tests and emphasized subthreshold assessments.

Studies examining the relation between somatization and alexithymia report that patients with somatization symptoms are finding it difficult to identify physical sensations occurring as bodily component of affect. While there are results supporting the idea that difficulties in identifying feelings may cause somatization symptoms, it has also been reported that alexithymia can cause or predispose towards the development of somatic symptoms independently from anxiety and depression (6).

Reviewing the literature on alexithymia and substance use disorder, we find the view that difficulties in emotional regulation are closely related to substance used (48). While there are different accounts in the literature, individuals with substance addiction disorder are experiencing more problems in emotional regulation than non-addicted persons (36). Alexithymia is seen as a factor to predict the substance use risk as well as affecting the period of abstinence and relapse (36). One research presented misinterpretation of bodily sensations and alexithymia as risk factors for alcohol abuse (49). To our knowledge, there are no studies in the literature assessing the relation between somatization and alexithymia in alcohol and substance addicts. However, studies in nonaddicts have maintained that alexithymia irrespective of depression and anxiety may cause somatic symptoms. Our study in addicted individuals supports a similar relation. However, the available data do not permit an interpretation regarding the mediating role of substance use in the relation between alexithymia and somatization.

This study has pointed towards anxiety and alexithymia symptoms as predictors for somatization symptoms in heroin and alcohol addicts. Nevertheless, we have not been able to provide evidence that somatization symptoms represent an underlying primary anxiety disorder in alcohol and heroin addicts. However, our study can lead to the conclusion that alcohol and heroin addicts with somatization symptoms need to be screened for the presence of primary anxiety disorder.

Evidently, this issue has not yet been sufficiently researched. It has only been addressed by a single study (44). Related studies either did not address this aspect directly or included other factors that could influence the results.

Female patients, patients being hospitalized for detoxification or without receiving treatment were excluded from our study. As some of the instruments administered were screening tests using self-assessment, they relied on patients' subjective reporting. In addition, using the mean SCL-90 score for all patients rather than for those who scored above the cutoff point for each subcategory may have increased the limitation. In the absence of a control group, differences in somatization, alexithymia, depression, and anxiety between heroin and alcohol addicts and healthy participants could not be determined. The two groups in our study differed in some sociodemographic data such as age and socioeconomic level. While we tried to optimize duration of treatment, very long abstinence periods were more common especially in alcohol addicts, which may have constituted a limitation. Furthermore, a twoweek abstinence period may not have been sufficient for the withdrawal symptoms to resolve completely in some patients. Thus, in certain cases it was difficult to specify if anxiety, depression, and somatic symptoms were related with withdrawal, which would have affected the results. Another limitation could be that around one third of alcohol addicts were using antidepressants, which could have led to a better clinical presentation during treatment.

In summary, patients with heroin addiction were found to have a lower severity of addiction than alcohol addicts but displayed more somatization, depression, interpersonal sensitivity, anger and hostility, psychoticism, and psychiatric symptoms. Our first hypothesis has been confirmed. Furthermore, in all alcohol and heroin addicts the planned regression model found that anxiety and alexithymia symptoms were significant predictors for somatization, while no significant predictive power of addiction severity and depression were found. Our second hypothesis could be partly confirmed.

The aim should be to include women, inpatients, and untreated alcohol and heroin addicts into these studies. Studies optimizing abstinence periods and treatment states could produce more stable results. In addition, there is a need for prospective studies investigating the course of somatization symptoms in alcohol and heroin addicts and studies with larger patient numbers to obtain more socially representative data.

To conclude, with addictions caused by different addictive substances, the potential occurrence of various psychiatric symptoms needs to be considered. 
Furthermore, it may be useful to screen heroin and alcohol addicts with high somatic symptoms for anxiety disorders and alexithymic personality traits.

\begin{tabular}{|c|c|c|}
\hline \multicolumn{2}{|c|}{ Contribution Categories } & Author Initials \\
\hline \multirow{3}{*}{ Category 1} & Concept/Design & M.H.A., Z.A. \\
\hline & Data acquisition & M.H.A., B.K., S.Y.S., I.V.S. \\
\hline & Data analysis/Interpretation & M.H.A., BC., C.U. \\
\hline \multirow{2}{*}{ Category 2} & Drafting manuscript & M.H.A., B.K., C.U. \\
\hline & Critical revision of manuscript & Z.A., B.C., I.V.S., S.Y.S. \\
\hline Category 3 & Final approval and accountability & $\begin{array}{l}\text { M.H.A., S.Y.S., I.V.S., B.K. } \\
\text { C.U., B.C., Z.A. }\end{array}$ \\
\hline \multirow{2}{*}{ Other } & Technical or material support & N/A \\
\hline & Supervision & Z.A., B.C. \\
\hline
\end{tabular}

Ethics Committee Approval: The study was approved by the ethics committee of Gazi University, date February 2, 2017, research code number 2017-85.

Informed Consent: Written informed consent was obtained from the patient.

Peer-review: Externally peer-reviewed.

Conflict of Interest: There is no conflict of interest.

Financial Disclosure: No funding declared.

\section{REFERENCES}

1. Maremmani I, Pani PP, Pacini M, Bizzarri JV, Trogu E, Maremmani AG, et al. Subtyping patients with heroin addiction at treatment entry: factor derived from the Self-Report Symptom Inventory (SCL-90). Ann Gen Psychiatry 2010 Apr 13;9:15.

2. Harris KM, Edlund MJ. Use of mental health care and substance abuse treatment among adults with co-occurring disorders. Psychiatr Serv 2005; 56:954-959.

3. Kelly TM, Daley DC. Integrated treatment of substance use and psychiatric disorders. Soc Work Public Health 2013; 28:388-406.

4. Hagen E, Erga AH, Hagen KP, Nesvåg SM, McKay JR, Lundervold $\mathrm{AJ}$, et al. One-year sobriety improves satisfaction with life, executive functions and psychological distress among patients with polysubstance use disorder. J Subst Abuse Treat 2017; 76:81-87.

5. Yavuz M, Erdur B, Isik M, Bogday H, Ince H, Kok O, et al. The associations between somatization, alexithymia, and mental problems in adolescents. Anatol J Psychiatry 2018; 1.

6. Kandemir G, Ak I. Psychiatric aspects of medically unexplained symptoms. Current Approaches to Psychiatry 2013; 5:479-506. (Turkish)

7. Lipowski ZJ. Somatization: the concept and its clinical application. Am J Psychiatry 1988; 145:1358-1368.

8. Lipowski ZJ. Somatization and depression. Psychosomatics 1990; 31:13-21.

9. Ross HE, Cutler M, Sklar SM. Retention in substance abuse treatment. Role of psychiatric symptom severity. Am J Addict 1997; 6:293-303.
10. Tien AY, Schlaepfer TE, Fisch HU. Self-reported somatization symptoms associated with risk for extreme alcohol use. Arch Fam Med 1998; 7:33-37.

11. Pani PP, Maremmani AG, Trogu E, Vigna-Taglianti F, Mathis F, Diecidue R, et al. Psychopathology of addiction: May a SCL-90based five dimensions structure be applied irrespectively of the involved drug? Ann Gen Psychiatry 2016; 15:13.

12. Taylor GJ. Recent developments in alexithymia theory and research. Can J Psychiatry 2000; 45:134-142.

13. Parker JD, Taylor GJ, Bagby RM. Alexithymia: relationship with ego defense and coping styles. Compr Psychiatry 1998; 39:91-98.

14. Taylor GJ, Bagby RM, Parker JDA, Grotstein J (Foreword). Disorders of Affect Regulation: Alexithymia in Medical and Psychiatric Illness. Cambridge: Cambridge University Press, 1997.

15. El Rasheed AH. Alexithymia in Egyptian Substance Abusers. Subst Abus 2001; 22:11-21.

16. Cleland C, Magura S, Foote J, Rosenblum A, Kosanke N. Psychometric properties of the Toronto Alexithymia Scale (TAS20) for substance users. J Psychosom Res 2005; 58:299-306.

17. De Rick A, Vanheule S. The relationship between perceived parenting, adult attachment style and alexithymia in alcoholic inpatients. Addict Behav 2006; 31:1265-1270.

18. Regier DA, Farmer ME, Rae DS, Locke BZ, Keith SJ, Judd LL, et al. Comorbidity of mental disorders with alcohol and other drug abuse. Results from the Epidemiologic Catchment Area (ECA) Study. JAMA 1990; 264:2511-2518.

19. Thorberg FA, Young RM, Sullivan KA, Lyvers M. Alexithymia and alcohol use disorders: a critical review. Addict Behav 2009; $34: 237-245$.

20. Freyberger H. Supportive psychotherapeutic techniques in primary and secondary alexithymia. Psychother Psychosom 1977; 28:337-42.

21. Honkalampi K, Hintikka J, Saarinen P, Lehtonen J, Viinamäki H. Is alexithymia a permanent feature in depressed patients? Results from a 6-month follow-up study. Psychother Psychosom 2000; 69:303-308.

22. Honkalampi K, Hintikka J, Tanskanen A, Lehtonen J, Viinamäki $\mathrm{H}$. Depression is strongly associated with alexithymia in the general population. J Psychosom Res 2000; 48:99-104.

23. Shipko S. Alexithymia and somatization. Psychother Psychosom 1982; 37:193-201.

24. Hasin D, Katz H. Somatoform and substance use disorders. Psychosom Med 2007; 69:870-875.

25. Ogel K, Evren C, Karadag F, Gurol DT. The development, validity, and reliability of the Addiction Profile Index (API). Turk Psikyatri Derg 2012; 23:264-273. (Turkish)

26. Ogel K, Koc C, Basabak A, Ismen EM, Gorucu S. Development of Addiction Profile Index (BAPI) Clinical Form: reliability and validity study. Journal of Dependence 2015; 16:57-69. (Turkish)

27. Derogatis LR. Symptom Checklist-90-R (SCL-90-R): Administration, scoring, and procedures manual. Third ed., Minneapolis, MN NCS Pearson, 1994. 
28. Dag I. Symptom Checklist-90-R: validity and reliability. Turk Psikolojik Danisma ve Rehberlik Dergisi 1991; 1:45-52. (Turkish)

29. Bagby RM, Taylor GJ, Parker JD, Dickens SE. The development of the Toronto Structured Interview for Alexithymia: item selection, factor structure, reliability and concurrent validity. Psychother Psychosom 2006; 75:25-39.

30. Gulec H, Kose S, Gulec MY, Citak S, Evren C, Borckardt J, Sayar $\mathrm{K}$. Reliability and factorial validity of the Turkish version of the 20-item Toronto Alexithymia Scale (TAS-20). Bulletin of Clinical Psychopharmacology 2009; 19:214-20.

31. Asan O, Tikir B, Okay I, Goka E. Sociodemographic and clinical features of patients with alcohol and substance use disorders in a specialized unit. Journal of Dependence 2015; 16:1-8. (Turkish)

32. Swendsen J, Conway KP, Degenhardt L, Dierker L, Glantz M, Jin $\mathrm{R}$, et al. Socio-demographic risk factors for alcohol and drug dependence: the 10-year follow-up of the national comorbidity survey. Addiction 2009; 104:1346-1355.

33. Border R, Corley RP, Brown SA, Hewitt JK, Hopfer CJ, McWilliams SK, et al. Independent predictors of mortality in adolescents ascertained for conduct disorder and substance use problems, their siblings and community controls. Addiction 2018; 113:2107-2115.

34. Pektas O, Kalyoncu A, Mirsal H, Beyazyurek M. Sociodemographic variables, clinical features, and treatment outcomes between two sexes in alcohol dependent patients. Journal of Dependence 2001; 2:25-29.

35. Evren C, Evren B, Yancar C, Erkiran M. Temperament and character model of personality profile of alcohol- and drugdependent inpatients. Compr Psychiatry 2007; 48:283-288.

36. Emiral E. Assessment of Codependency and Alexithymia within the Frame. Bagimlilik Dergisi - Journal of Dependence 2019; 20:109-118. (Turkish)

37. Soyka M, Strehle J, Rehm J, Bühringer G, Wittchen HU. Six-Year Outcome of Opioid Maintenance Treatment in Heroin-Dependent Patients: Results from a Naturalistic Study in a Nationally Representative Sample. Eur Addict Res 2017; 23:97-105.

38. Leach D, Kranzler HR. An Interpersonal Model of Addiction Relapse. Addict Disord Their Treat 2013; 12:183-192.
39. Evren C, Ogel K. Dissociative symptoms among alcohol and substance dependents and its relationships with childhood trauma history, depression, anxiety, and alcohol/substance use. Anadolu Psikiyatr Derg 2003; 4:30-37. (Turkish)

40. Swendsen JD, Merikangas KR. The comorbidity of depression and substance use disorders. Clin Psychol Rev 2000; 20:173-189.

41. Bácskai E, Czobor P, Gerevich J. Gender differences in trait aggression in young adults with drug and alcohol dependence compared to the general population. Prog Neuropsychopharmacol Biol Psychiatry 2011; 35:1333-1340.

42. Smith MJ, Thirthalli J, Abdallah AB, Murray RM, Cottler LB. Prevalence of psychotic symptoms in substance users: a comparison across substances. Compr Psychiatry 2009; 50:245250 .

43. Metrikin AS, Galanter M, Dermatis H, Bunt G. Somatization, anxiety and depression in a drug-free residential therapeutic community. Am J Addict 2003; 12:60-70.

44. Hassan I, Ali R. The association between somatic symptoms, anxiety disorders and substance use. A literature review. Psychiatr Q 2011; 82:315-328.

45. Escobar JI, Rubio-Stipec M, Canino G, Karno M. Somatic symptom index (SSI): a new and abridged somatization construct. Prevalence and epidemiological correlates in two large community samples. J Nerv Ment Dis 1989; 177:140-146.

46. Lieb R, Pfister H, Mastaler M, Wittchen HU. Somatoform syndromes and disorders in a representative population sample of adolescents and young adults: prevalence, comorbidity and impairments. Acta Psychiatr Scand 2000; 101:194-208.

47. Simon GE, VonKorff M. Somatization and psychiatric disorder in the NIMH Epidemiologic Catchment Area study. Am J Psychiatry 1991; 148:1494-1500.

48. Bonn-Miller MO, Vujanovic AA, Zvolensky MJ. Emotional dysregulation: association with coping-oriented marijuana use motives among current marijuana users. Subst Use Misuse. 2008; 43:1653-1665.

49. Betka S, Pfeifer G, Garfinkel S, Prins H, Bond R, Sequeira H, et al. How do self-assessment of alexithymia and sensitivity to bodily sensations relate to alcohol consumption? Alcohol Clin Exp Res. 2018; 42:81-88 